\title{
Factors affecting online accounting education during the COVID-19 pandemic: an integrated perspective of social capital theory, the theory of reasoned action and the technology acceptance model
}

\author{
Hashem Alshurafat $^{1}$ (D) Mohannad Obeid Al Shbail ${ }^{2}$ (D) \\ Walid Muhammad Masadeh ${ }^{1}$ (D) Firas Dahmash ${ }^{1}$ (D) \\ Jebreel Mohammad Al-Msiedeen ${ }^{3}$
}

Received: 27 November 2020 / Accepted: 13 April 2021 / Published online: 26 April 2021

(C) The Author(s), under exclusive licence to Springer Science+Business Media, LLC, part of Springer Nature 2021

\begin{abstract}
Online learning systems in developing countries such as Jordan face many challenges. Universities worldwide have dealt with obstacles in terms of continuing face-to-face education. An online learning system is an indispensable solution for all universities. However, students have not been adequately prepared to use online learning systems. This study examines the factors that impact the use of online learning systems by accounting students in Jordanian public universities. A model combining the critical factors from social capital theory (SCT), the theory of reasoned action (TRA), and the technology acceptance model (TAM) is proposed. Data obtained from 274 students through previously tested and validated questionnaires are used to test students' actual use of the online learning system and to determine the factors that positively or negatively impact the use of this system. As hypothesized, the results show that social trust influences the perceived usefulness and perceived ease of use of online learning. In addition, the perceived usefulness of the online learning system is positively affected by its perceived ease of use and subjective norms. This study finds three significant predictors of attitudes toward use decisions: subjective norms, perceived ease of use, and perceived usefulness. The results are valuable to accounting educators, accounting students, universities, and higher education institutions.
\end{abstract}

Keywords Online learning system $\cdot$ Accounting education $\cdot$ Higher education institutions · Universities - Developing countries

Hashem Alshurafat

hashema@hu.edu.jo

Extended author information available on the last page of the article 


\section{Introduction}

In most developing countries, it is not uncommon for instructors and students to face difficulties in engaging in meaningful traditional teaching processes. These difficulties may include a lack of interest and motivation among students (Alshurafat et al., 2020; Bidabadi et al., 2016). Similarly, delivering knowledge content and assessing students' performance through an online learning system are complicated processes, particularly when instructors and students are not prepared (Aisbitt \& Sangster, 2005; Barnard-Brak et al., 2010; Litherland et al., 2013). In March 2020, like universities worldwide, universities in Jordan were overwhelmed by the massive impact of the COVID-19 pandemic, which affected vital sectors (e.g., the educational and economic sectors) (Gruszczynski, 2020; Torsello \& Winkler, 2020). Consequently, universities in Jordan chose to adopt an online learning system to continue the educational process. This sudden adoption of an online learning system received mixed reactions from both instructors and students. Some students were not convinced of its benefits or qualified to cope with the application of the online learning system. Therefore, the learning process was changed for some individuals and temporarily ceased for others as they faced multiple barriers to their ability to use and adopt the online learning system. This study aims to understand the factors that affect students' adoption of online learning systems.

Proponents of online learning systems believe that they have the potential to enhance faculty productivity and reduce instructional costs without compromising academic integrity (Bacow et al., 2012). Despite the benefits of online learning systems, Means et al. (2009) argue that these systems are considered less productive at traditional colleges and universities. This is also true for universities in Jordan. Most universities in Jordan had not fully adopted online learning systems before the coronavirus outbreak. Thus, the current adoption of an online learning system in the accounting and business departments may have a negative influence on the educational process.

Prior research has focused on the challenges and factors that hinder the adoption and use of online learning systems without extraordinary circumstances that might affect their adoption and use (Abdekhoda et al., 2016; Al-Rahmi et al., 2019; Bacow et al., 2012a, b; Gómez-Ramirez et al., 2019; Moore et al., 2011; Yadegaridehkordi et al., 2019). There is a lack of agreement among educators about the determinants of the successful adoption and use of online learning systems during the COVID-19 pandemic, and a clear gap has been recognized in knowledge of the significant factors in the use of these systems during this pandemic. Therefore, this research explores the significant factors that promote the current usage of online learning systems during the COVID-19 pandemic.

The decision to choose Jordan was made for the following reasons. First, Jordan is considered one of the developing countries that has a promising educational sector. The educational sector in Jordan contributes to the overall economy and is considered one of the best educational sectors in the region (Al-Qadi \& Lozi, 2017; Simadi \& Nahar, 2009). Second, although many studies exist on 
online learning systems, this study aims to provide a novel contribution to the current literature on the main hurdles and determinants that affect the successful adoption of online learning systems in a new context, Jordan, which may exemplify other developing countries. Third, similar to other developing countries, adoption and usage of online learning systems remain low in Jordan.

This study has practical implications for reforming the adoption process of online learning systems by providing guidelines for overcoming the challenges of the sudden adoption of these systems. This research contributes to faculty and staff's understanding of the factors that affect the actual use of the online learning system by accounting students, thus enhancing the quality of the educational process during the COVID-19 outbreak. The remainder of this paper is organized as follows. The next section reviews the literature on online learning systems and presents this study's theoretical background. Section three describes the research method. Section four presents the results of this research. Section five provides a discussion of the results. The final section concludes the paper.

\section{Literature review}

\subsection{Online learning systems and the use of technology in teaching and assessment}

Many rigorous studies have been published on the effectiveness and obstacles of online learning systems for university students. An online learning system is defined in the literature as "access to learning experiences via the use of some technology" (Moore et al., 2011, p 130). The advent of the internet and the huge development of technology have underscored the use of online learning systems, e-learning, and other forms of distance learning that are based on technological solutions (Bacow et al., 2012a, b; Humphrey \& Beard, 2014; Moore et al., 2011; Yadegaridehkordi et al., 2019). For example, some universities have developed courses that merge the benefits of online teaching with traditional face-to-face (F2F) teaching (Fortin et al., 2019; Love \& Fry, 2006; Peng \& Abdullah, 2018). Online learning systems have vital importance and wide benefits, such as increased knowledge of technology, improved quality of instruction, improved learning outcomes, flexibility, and control (Fortin et al., 2019; Turnbull et al., 2021). Chugh (2010, p 58) stated,

"E-learning is a situated activity that occurs in various settings and, if implemented appropriately, can provide an ideal environment facilitating social interaction whilst also providing academic, social, and psychological benefits".

Technology is particularly crucial to accounting curricula, and many technologies are relevant to these curricula. For example, Chugh (2010) cited relevant technologies for accounting curricula, including blogs, wikis, bulletin board systems, electronic mail, audio podcasting (podcasts), video podcasting (vodcasts), chat rooms, audio conferencing, and video conferencing. Kotb et al. (2019) noted that IT represents an essential area that should be covered in accounting curricula to address 
modifications in the marketplace and to promote graduates' employability. This view is supported by Uwizeyemungu et al. (2020), who found that technology is one of seven essential competencies required by accountant recruiters. The use of technology and an online learning system in assessment is appreciated by students (Helfaya, 2019), and accounting students' performance improves with online exams (Aisbitt $\&$ Sangster, 2005). There is a positive and significant relationship between the time that the students spend using online educational platforms and their performance in the final examination in accounting courses (Perera \& Richardson, 2010). This evidence is supported by Duncan et al. (2012), who found that the performance of accounting students is enhanced during online examinations, especially in courses that encompass synchronous and asynchronous interactions between students.

It is argued that online learning systems have many benefits, such as the lower cost of the educational process, flexible access to instructional materials, and response to space constraints (Anderson, 2008; Bacow et al., 2012b; Means et al., 2009; Moore et al., 2011). By contrast, some prior studies have indicated the obstacles of online learning systems. These obstacles may include the high cost of implementing online learning systems (Turnbull et al., 2021). Moreover, an online learning system requires a high level of coordination by students and instructors. In addition, accrediting bodies do not support online learning systems and teaching in traditional university settings (Allen \& Seaman, 2007; Bacow et al., 2012b; Garrison, 2003; Moore et al., 2011; Perera \& Richardson, 2010). Almaiah et al. (2020) reported several challenges to the adoption of online learning systems, including lack of financial support, lack of trust, managerial problems, and technological challenges.

\subsection{Research model}

This study integrates social capital theory (SCT), the theory of reasoned action (TRA), and the technology acceptance model (TAM) to examine accounting students' intention to use a university online learning system. Despite the extensive application of SCT, the TRA, and the TAM in research studies, few, if any, studies have explored their integration to predict and explain students' intention to use online learning systems in developing countries. Therefore, this study aims to explore the integration of SCT, TRA, and TAM to predict and explain accounting students' intention to use an online learning system in public Jordanian universities, as shown in Fig. 1.

\subsection{Hypotheses development}

In this research context, the theoretical model hypothesizes that the level of social trust affects both the perceived usefulness and the perceived ease of use. Social trust is not an original construct of the TAM or the TRA model. However, social trust is recognized as a significant factor that affects perceived usefulness and perceived ease of use (Dumpit \& Fernandez, 2017; Venkatesh et al., 2003). Perceived usefulness is defined by Davis (1989, p. 320) as "the degree to which a person believes 


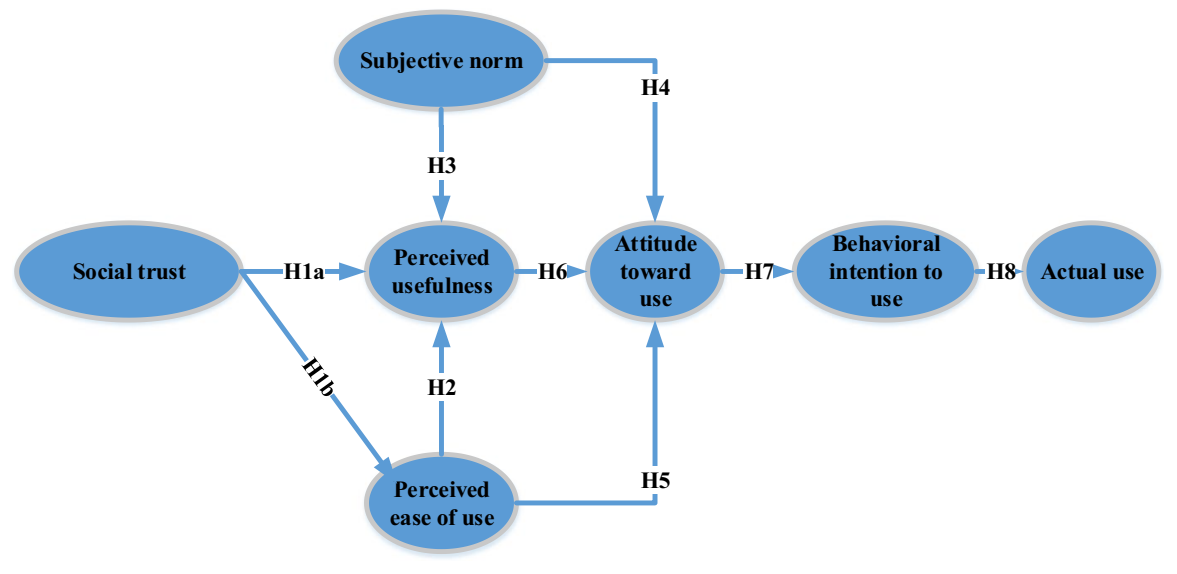

Fig. 1 The research theoretical framework

that using a particular system would enhance his or her job performance". This construct is based on the extent to which technology allows users to complete tasks faster, improve productivity, and enhance performance and efficiency (Bierstaker et al., 2014; Mahzan \& Lymer, 2014). The perceived ease of use of technology is defined by Davis (1989, p. 320) as "the degree to which a person believes that using a particular system would be free of effort". It is evident that the ease of use of technology significantly impacts its perceived usefulness (Davis, 1989; Davis et al., 1989; Venkatesh et al., 2003). Pedrosa et al. (2020) confirmed this relationship in a study that investigated the determinants of the use of computer-assisted auditing tools (CAATs) in the context of statutory auditors of a European country. On this foundation, the following hypotheses are formulated:

Hypothesis 1A: High social trust leads to high perceived usefulness.

Hypothesis 1B: High social trust leads to high perceived ease of use.

Hypothesis 2: High perceived ease of use leads to high perceived usefulness.

Social influence is defined by Venkatesh et al. (2003, p. 451) as "the degree to which an individual perceives that important others believe he or she should use [a] new system". Lee (2006) found that the effects of subjective norms significantly influence the perceived usefulness construct. Thus, the following hypothesis is formulated:

Hypothesis 3: High influence from family and other important people leads to high perceived usefulness.

In this research context, the attitude toward technology use is believed to be influenced by three main factors, namely, perceived usefulness, subjective norms, and 
perceived ease of use. Hsbollah and Idris (2009) investigated the factors that affect lecturers' adoption of online learning systems. They found that among multiple factors, perceived advantage (relative advantage) is an influential factor in adopting online learning systems. Similarly, the impacts of perceived ease of use on behavioral attitudes toward use have been confirmed in many previous studies in various organizational and individual contexts (Ahmi \& Kent, 2013; Bierstaker et al., 2014). Liu et al. (2010) found that perceived ease of use and perceived usefulness are influential factors in students' intention to use online learning systems. Similarly, Yadegaridehkordi et al. (2019) found that the intention to adopt online collaborative learning tools in higher education is significantly affected by perceived usefulness. Thus, the following hypotheses are formulated:

Hypothesis 4: High influence from family and other important people leads to a highly positive attitude toward use.

Hypothesis 5: High perceived ease of use leads to a highly positive attitude toward use.

Hypothesis 6: High perceived usefulness leads to a highly positive attitude toward use.

Davis et al. (1989) found that the attitude toward using a system impacts the behavioral intention to use the system. This relationship has been consistent in many studies (Bierstaker et al., 2014; Gangwar et al., 2015; Hsbollah, 2009; Lee, 2006; Munoz-Leiva et al., 2017; Pedrosa et al., 2020; Venkatesh et al., 2003). Therefore, the following hypothesis is formulated:

Hypothesis 7: A highly positive attitude toward use leads to the behavioral intention to use.

According to Ajzen and Fishbein (1980), the behavioral intention to use determines the actual usage of technology. The TRA and TAM theoretical models also emphasize this relationship (Davis, 1989). It is empirically evident in most studies of online learning systems that actual use is primarily affected by the behavioral intention to use (Hsbollah, 2009; Lee, 2006; Liu et al., 2010). Therefore, the following hypothesis is formulated:

Hypothesis 8: High behavioral intention to use leads to actual usage.

\section{Methodology}

\subsection{Sampling and data collection}

In this study, data on the use of an online learning system were gathered over a span of two months, from July 2020 to September 2020, from accounting students in Jordanian public universities. A questionnaire was used as the primary data collection 
instrument, and copies were distributed online through Microsoft Forms. The completed questionnaires were returned by 319 students within a couple of months. After a review of the content of the responses, 45 responses were excluded due to insufficient information or missing data. A total of 274 questionnaires were used for further statistical analysis.

Before the data were collected, the questionnaire was designed in both English and Arabic, which are the official and formal languages used for teaching accounting in Jordanian public universities. The research team comprised individuals fluent in both languages, eliminating the need for a panel of experts. As accounting lecturers, the research team held deep insight into the online learning system. There was no need to distinguish the participants based on their universities. As an initial step, the authors forwarded the questionnaire to 15 accounting professors working in different Jordanian public universities, and a pilot test was conducted with 35 participants to determine instrument issues in terms of wording, content, and ambiguity. Their feedback was used to make minor changes to the survey. The final questionnaire had three sections, namely, an introduction, sociodemographic information, and construct measurements, with the constructs in the third section measured using a 7-point Likert scale.

\subsection{Measurement development}

The instrument had four parts (see Appendix 1). The first part contained nominal scales because it collected basic information, while the remaining parts were measured using 7-point Likert scales. The first part contained general basic information questions designed to gather the students' characteristics (e.g., gender and age). This was followed by the second section as shown in Table 1, which contained four items that measured PU and PEOU in the TAM (Davis, 1989; Venkatesh \& Davis, 1996, 2000). There were also four items used to measure intention toward the use of the online learning systems of the universities adopted from Lin (2011) and two items to measure actual online learning system use adopted from Hubona and Kennick (1996) and Moon and Kim (2001). The frequency of use represented the number of hours per week the respondents used the system.

The third section included attitude and SN items adopted from Ajzen (1991), Pavlou (2003), and Taylor and Todd (1995), with both measured by five items. The instrument's final section was dedicated to SCT, with social trust gauged by three items adapted from Mathwick et al. (2008).

\subsection{Common method variance test}

The common method variance (CMV) test is important for cross-sectional surveys (Akter et al., 2011) and is conducted through the assessment of full collinearity (Kock \& Lynn, 2012). Table 3 displays the multicollinearity assessment result obtained with the variance inflation factor (VIF). The table shows that VIF values did not exceed 5 when regressing a dummy variable against the model's variables 
Table 1 Measures and Operationalizations

\begin{tabular}{|c|c|}
\hline Construct & Items \\
\hline Perceived Usefulness (PU) & $\begin{array}{l}\text { Using the university online learning system supports a critical part of my } \\
\text { student life } \\
\text { Using the university online learning system enables me to access a lot of } \\
\text { facilities (e.g., library) within my student life } \\
\text { Using the university online learning system will improve services (fast } \\
\text { speeds) and save time } \\
\text { Overall, the university online learning system is useful }\end{array}$ \\
\hline Perceived Ease-of-Use (PEU) & $\begin{array}{l}\text { It is easy for me to use the university online learning system } \\
\text { It is easy to learn how to use the university online learning system } \\
\text { It is easy to remember how to use the university online learning system } \\
\text { Overall, the university online learning system is easy to use }\end{array}$ \\
\hline Subjective Norms (SN) & $\begin{array}{l}\text { People who are important to me would think that I should use the univer- } \\
\text { sity online learning system } \\
\text { People who are influential to me would think that I should use the univer- } \\
\text { sity online learning system } \\
\text { People whose opinions are valued by me would prefer that I use the } \\
\text { university online learning system } \\
\text { People around me have encouraged me to use the university online learn- } \\
\text { ing system } \\
\text { Most students in my group/department use the University online learning } \\
\text { system frequently }\end{array}$ \\
\hline Social Trust (ST) & $\begin{array}{l}\text { I trust the university online learning system to know things I do not know } \\
\text { I would base an important decision on advice I received from the univer- } \\
\text { sity online learning system } \\
\text { The university online learning system has high integrity }\end{array}$ \\
\hline Attitude (AT) & $\begin{array}{l}\text { I always enjoy using the university online learning system } \\
\text { I am positive about using the university online learning system } \\
\text { I think that using the university online learning system is a good idea } \\
\text { I want to be among the first people to try out new functions of the univer- } \\
\text { sity online learning system } \\
\text { I always consider the university online learning system as my first choice }\end{array}$ \\
\hline Intention to use (INT) & $\begin{array}{l}\text { I will definitively keep using the university online learning system } \\
\text { I will use the university online learning system on a regular basis in the } \\
\text { future } \\
\text { I expect that the university online learning system will make everything } \\
\text { easier in the future } \\
\text { It is worth using the university online learning system }\end{array}$ \\
\hline Actual usage (AU) & $\begin{array}{l}\text { How often per week do you visit the university online learning system? } \\
\text { How many hours do you use the university online learning system every } \\
\text { week? }\end{array}$ \\
\hline
\end{tabular}


(Hair et al., 2016). This indicates that CMV was a nonissue and ensures that there was no distortion of meaning in the survey measures by the data.

\subsection{Data analysis}

The valid responses were subjected to partial least squares-structural equation modeling (PLS-SEM) analysis according to Hair et al.'s (2016) recommendation. This analysis is widely utilized in the behavioral and social sciences due to its capability to model latent variables, rectify measurement errors, and estimate all model parameters at the same time. Specifically, the study used SmartPLS 3.2.8 for model measurement for the determination of the relevant structural equations following the guidelines established by Sarstedt and Cheah (2019).

\section{Analysis and findings}

The respondents' profile is presented in Table 2. Based on the table, female respondents constituted $51.8 \%$ of the total respondents, while the remaining respondents $(48.2 \%)$ were male. The majority of the respondents had academic achievement that ranged from good to very good, and the majority of them held bachelor's degrees.

Table 2 Respondents' profile

\begin{tabular}{lllr}
\hline Demographic variables & Category & Frequency & $(\%)$ \\
\hline Gender & Male & 142 & 51.8 \\
Program & Female & 132 & 48.2 \\
& Bachelor & 252 & 92.0 \\
Academic year & Master & 22 & 8.0 \\
& Bachelor (first year) & 58 & 21.1 \\
& Bachelor (second year) & 67 & 24.4 \\
& Bachelor (third year) & 49 & 17.9 \\
& Bachelor (fourth year) & 78 & 28.5 \\
Academic achievement & Master (first year) & 14 & 5.1 \\
& Master (second year) & 8 & 2.9 \\
& Weak & 12 & 4.4 \\
& Acceptable & 27 & 9.9 \\
& Good & 113 & 41.2 \\
& Very good & 89 & 32.5 \\
Specialization & Excellent & 33 & 12.0 \\
& Accounting & 91 & 33.2 \\
& Accounting and commercial law & 76 & 27.7 \\
& Accounting and business law & 81 & 29.6 \\
& Accounting information systems & 26 & 9.5 \\
\hline
\end{tabular}




\subsection{Measurement model results}

This study assessed the measurement model/outer model by observing the individual measurement item factor loadings, Cronbach's alpha values, and their composite reliability (CR) values, with average variance extracted (AVE) for the confirmation of convergent validity (Hair et al., 2016). Moreover, the research model's discriminant validity was confirmed through the use of the Fornell and Larcker (1981) criterion and the heterotrait and monotrait (HTMT) ratio, as suggested by prior literature (e.g., Franke \& Sarstedt, 2019; Henseler et al., 2015; Shbail \& Shbail, 2020). Table 3 presents the results of the analysis and shows a good level of internal consistency, with Cronbach's alpha and CR values exceeding 0.71, satisfying the rule of thumb provided by Nunnally (1994). Additionally, individual item loadings were over 0.70 and were highly significant $(\mathrm{p}<0.001)$, except for item 5 of subjective norms (SN-5), which was ultimately removed. For the AVE criterion, the AVE

Table 3 Measurement model results

\begin{tabular}{|c|c|c|c|c|c|c|c|}
\hline Construct & Code & Loadings & VIF & $\mathrm{P}$-value & $\mathrm{CA}$ & CR & AVE \\
\hline \multirow[t]{3}{*}{ Social trust } & ST-1 & 0.861 & 1.798 & $<0.000$ & 0.797 & 0.881 & 0.711 \\
\hline & ST-2 & 0.874 & 1.893 & $<0.000$ & & & \\
\hline & ST-3 & 0.793 & 1.533 & $<0.000$ & & & \\
\hline \multirow[t]{4}{*}{ Subjective norms } & SN-1 & 0.862 & 3.209 & $<0.000$ & 0.867 & 0.909 & 0.715 \\
\hline & $\mathrm{SN}-2$ & 0.858 & 3.220 & $<0.000$ & & & \\
\hline & SN-3 & 0.838 & 2.019 & $<0.000$ & & & \\
\hline & $\mathrm{SN}-4$ & 0.823 & 1.893 & $<0.000$ & & & \\
\hline \multirow[t]{4}{*}{ Perceived usefulness } & PU-1 & 0.837 & 1.949 & $<0.000$ & 0.825 & 0.884 & 0.657 \\
\hline & PU-2 & 0.706 & 1.441 & $<0.000$ & & & \\
\hline & PU-3 & 0.866 & 2.155 & $<0.000$ & & & \\
\hline & PU-4 & 0.823 & 1.803 & $<0.000$ & & & \\
\hline \multirow[t]{4}{*}{ Perceived ease of use } & PEU-1 & 0.880 & 2.510 & $<0.000$ & 0.908 & 0.936 & 0.785 \\
\hline & PEU-2 & 0.904 & 3.399 & $<0.000$ & & & \\
\hline & PEU-3 & 0.902 & 3.222 & $<0.000$ & & & \\
\hline & PEU-4 & 0.856 & 2.286 & $<0.000$ & & & \\
\hline \multirow[t]{5}{*}{ Attitude toward use } & AT-1 & 0.856 & 2.798 & $<0.000$ & 0.911 & 0.934 & 0.739 \\
\hline & AT-2 & 0.901 & 3.769 & $<0.000$ & & & \\
\hline & AT-3 & 0.890 & 3.200 & $<0.000$ & & & \\
\hline & AT-4 & 0.814 & 2.050 & $<0.000$ & & & \\
\hline & AT-5 & 0.834 & 2.312 & $<0.000$ & & & \\
\hline \multirow[t]{4}{*}{ Intention to use } & INT-1 & 0.828 & 1.942 & $<0.000$ & 0.871 & 0.911 & 0.720 \\
\hline & INT-2 & 0.858 & 2.351 & $<0.000$ & & & \\
\hline & INT-3 & 0.851 & 2.094 & $<0.000$ & & & \\
\hline & INT-4 & 0.857 & 2.442 & $<0.000$ & & & \\
\hline \multirow[t]{2}{*}{ Actual usage } & AU-1 & 0.936 & 1.435 & $<0.000$ & 0.710 & 0.867 & 0.765 \\
\hline & AU-2 & 0.810 & 1.435 & $<0.000$ & & & \\
\hline
\end{tabular}


Table 4 Discriminant validity based on Fornell-Larcker criterion

\begin{tabular}{llllllll}
\hline & AT & AU & INT & PEU & PU & SN & ST \\
\hline Attitude toward use (AT) & 0.860 & & & & & & \\
Actual usage (AU) & 0.112 & 0.875 & & & & & \\
Intention to use (INT) & 0.414 & 0.143 & 0.849 & & & & \\
Perceived ease of use (PEU) & 0.513 & 0.120 & 0.266 & 0.886 & & & \\
Perceived usefulness (PU) & 0.723 & 0.090 & 0.424 & 0.536 & 0.810 & & \\
Subjective norms (SN) & 0.719 & 0.099 & 0.348 & 0.445 & 0.631 & 0.846 & \\
Social trust (ST) & 0.605 & 0.018 & 0.402 & 0.373 & 0.535 & 0.489 & 0.843 \\
\hline
\end{tabular}

scores of all constructs exceeded the 0.50 threshold (refer to Table 3 ), indicating the convergent validity of the model (Hair et al., 2016).

In Tables 4 and 5, the AVE square roots of the latent constructs are presented. The values were larger than the correlations of the corresponding latent variable (Fornell \& Larcker, 1981), with HTMT ratio values remaining under 0.90 (Franke \& Sarstedt, 2019; Henseler et al., 2015), indicating the presence of discriminant validity.

\subsection{Structural model results}

After the confirmation of the construct validity and reliability of the measurement model, the next step is the administration of a five-step approach to the structural model. VIF was used to examine the issue of collinearity. Table 3 shows that the VIF values all remained under the threshold of 5 as suggested by Hair et al. (2016), indicating the absence of any issue of multicollinearity.

Moving on to the results of the hypotheses testing, the bootstrapping method with 5000 resamplings was used, and the results are presented in Table 6. The results show positive effects on perceived usefulness from social trust (H1a: $\beta=0.242, t=4.821)$, subjective norms $(\mathrm{H} 3: \beta=0.391, t=7.827)$, and perceived ease of use $(\mathrm{H} 2$ : $\beta=0.271, t=5.707)$, while perceived ease of use was positively affected by social trust ( $\mathrm{H} 1 \mathrm{~b}: \beta=0.373, \mathrm{t}=6.605)$. Moreover, the three top predictors of attitude toward use were subjective norms $(H 4: \beta=0.416, t=8.478)$,

Table 5 Discriminant validity based on HTMT ratio

\begin{tabular}{llllllll}
\hline & AT & AU & INT & PEU & PU & SN & ST \\
\hline Attitude toward use (AT) & & & & & & & \\
Actual usage (AU) & 0.140 & & & & & & \\
Intention to use (INT) & 0.458 & 0.164 & & & & & \\
Perceived ease of use (PEU) & 0.562 & 0.155 & 0.295 & & & & \\
Perceived usefulness (PU) & 0.825 & 0.119 & 0.492 & 0.612 & & & \\
Subjective norms (SN) & 0.804 & 0.121 & 0.391 & 0.498 & 0.737 & \\
Social trust (ST) & 0.707 & 0.052 & 0.475 & 0.434 & 0.654 & 0.581 \\
\hline
\end{tabular}


Table 6 Results of hypothesis testing

\begin{tabular}{|c|c|c|c|c|c|}
\hline Structural path & $\beta$ and t-values & Conclusion & $f^{2}$ & $\mathrm{R}^{2}$ & $\mathrm{Q}^{2}$ \\
\hline H1a: ST $\longrightarrow$ PU & $0.242(4.821)$ & Accepted & 0.089 & 0.522 & 0.320 \\
\hline H1b: ST—PEU & $0.373(6.605)$ & Accepted & 0.162 & 0.139 & 0.101 \\
\hline $\mathrm{H} 2: \mathrm{PEU} \longrightarrow \mathrm{PU}$ & $0.271(5.707)$ & Accepted & 0.118 & & \\
\hline H3: SN-> PU & $0.391(7.827)$ & Accepted & 0.218 & & \\
\hline $\mathrm{H} 4: \mathrm{SN} \longrightarrow \mathrm{AT}$ & $0.416(8.478)$ & Accepted & 0.288 & 0.647 & 0.445 \\
\hline H5: PEU— $>$ AT & $0.114(2.559)$ & Accepted & 0.025 & & \\
\hline H6: PU— $\rightarrow$ AT & $0.400(7.500)$ & Accepted & 0.236 & & \\
\hline H7: AT $\longrightarrow>$ INT & $0.414(7.189)$ & Accepted & 0.207 & 0.172 & 0.110 \\
\hline H8: INT $\longrightarrow$ AU & $0.143(2.096)$ & Accepted & 0.021 & 0.020 & 0.012 \\
\hline
\end{tabular}

ST Social trust, PUPerceived usefulness, PEUPerceived ease-of-use, SNSubjective norms, AT Attitude toward use, INTIntention to use, $A U$ Actual usage

perceived ease of use $(\mathrm{H} 5: \beta=0.114, \mathrm{t}=2.559)$ and perceived usefulness (H6: $\beta=0.400, t=7.500)$. Attitude toward use had a significant direct effect on the behavioral intention to use $(\mathrm{H} 7: \beta=0.414, \mathrm{t}=7.189)$, while the latter had a positive relationship with actual usage $(\mathrm{H} 8: \beta=0.143, \mathrm{t}=2.096)$.

Table 6 shows that all predictors managed to explain the variance in perceived usefulness at $52.2 \%$, perceived ease of use at $13.9 \%$, attitude toward use at $64.7 \%$, behavioral intention to use at $17.2 \%$, and actual usage at $2.0 \%$.

Furthermore, the study assessed the effect size (f2) to cross-check each path's significance, as suggested by Sullivan and Feinn (2012) (see Table 6). Cohen (1988) established the guidelines for effect size (f2), where a value of 0.02 is small, 0.15 is medium, and 0.35 is large. From Table 6 , the effect size was found to be small for social trust ( $\mathrm{f} 2=0.089$ ) and perceived ease of use ( $\mathrm{f} 2=0.118$ ) and medium for subjective norms ( $\mathrm{f} 2=0.218$ ) in their generation of perceived usefulness R2. For the generation of perceived ease of use R2, a medium effect size of social trust was found $(\mathrm{f} 2=0.162)$. Adding to the above (f2) results, two out of three attitudes toward use predictors, subjective norms $(\mathrm{f} 2=0.288)$ and perceived usefulness ( $\mathrm{f} 2=0.236$ ), exhibited medium effect sizes. A small effect size was noted for perceived ease of use $(f 2=0.025)$ in the generation of attitudes toward use R2. With regard to intention toward use R2, a medium effect size was found for attitude toward use ( $\mathrm{f} 2=0.207)$, while a small effect size was noted for intention to use ( $\mathrm{f} 2=0.020$ ) for actual usage $\mathrm{R} 2$.

Finally, the study used a blindfolding procedure for the model's predictive relevance (Q2) assessment. The endogenous variable Q2 values varied from $0.012-0.445$ (exceeding 0), demonstrating the predictive quality of the model (Hair et al., 2016).

\section{Discussion}

An online learning system is an indispensable solution for educational institutions during the COVID-19 period. Therefore, from a closer look at this research's findings, it is evident that the students worked hard to overcome the challenges 
of the online learning system. However, multiple factors impact the degree of actual use of an online learning system (Almaiah et al., 2020; Bacow et al., 2012; Hsbollah, 2009; Yadegaridehkordi et al., 2019). This study examined the factors that influence the sudden adoption of an online learning system using an integrated theoretical framework that encompasses social capital theory (SCT), the theory of reasoned action (TRA), and the technology acceptance model (TAM). These theories are used to explain the adoption decision of the online learning system by students at Jordanian public universities.

The hypothesized relationships were empirically tested, and the results showed that social trust impacted the perceived usefulness and perceived ease of use of the online learning system. In addition, the perceived usefulness of the online learning system was positively affected by the ease of use of the online learning system and subjective norms. The results from this study are consistent with other studies in the field (Almaiah et al., 2020; Hsbollah, 2009; Lee, 2006; Martins et al., 2004). This study indicates that the attitude toward use as a dependent variable is well predicted by three major predictors: subjective norms, perceived ease of use, and perceived usefulness. This result confirms the theoretical evidence of the integrated theoretical framework of SCT, the TRA, and the TAM (Adams et al., 1992; Azjen \& Fishbein, 1980; Davis, 1989; Davis et al., 1989; Kwon \& Zmud, 1987; Venkatesh et al., 2003). Thus, it can be concluded that these are the three most significant factors that can make the sudden adoption and transformation to an online learning system a successful process.

Moreover, attitude toward use is a significant factor that impacts the behavioral intention to use, while the latter positively impacts actual usage. This is similar to the findings of Abdekhoda et al. (2016), Al-Ammari and Hamad (2008), Lee (2006), Turnbull et al. (2021), Almaiah et al. (2020), and Yadegaridehkordi et al. (2019). The implication of these findings is that students would show more acceptance of the online learning system if it was not adopted suddenly.

\section{Conclusion}

This study adds value to the current literature on online learning system adoption in the accounting education context by recognizing the main factors that enhance the successful usage of online learning systems during the COVID-19 pandemic. This research presents solid practical insights into the adoption and usage of online learning systems in developing countries such as Jordan. Factors that enhance the usage of online learning systems are not only confined to organizational issues, as suggested in previous research (Almaiah et al., 2020; Turnbull et al., 2021; Uwizeyemungu et al., 2020; Yadegaridehkordi et al., 2019), but also incorporate other factors, such as individual-related factors and technology-related issues. Therefore, the findings of this study offer valuable recommendations for policymakers, educators, and researchers and will enable them to be more informed about the key features of the successful adoption of online learning systems.

In terms of managerial implications of this study, Jordanian public universities should enhance the quality of the online learning system and simultaneously consider the factors 
that have been found to influence the use of online learning systems during the COVID19 period. First and foremost, control over students' social exposure will enhance their perception of the advantages and ease of using the online learning system, thus improving students' attitude toward using the online learning system. Second, instructors and educators are encouraged to explain the advantages of the online learning system to enhance students' acceptance of the use of the online learning system. Students also must be educated about how to use online learning system tools to facilitate the online learning system process. Third, online learning system designers should develop systems that are user-friendly, easy to use, and manageable because if users (students and instructors) find the online learning system easy to use, they are capable of effectively implementing the online learning system. Fourth, policymakers in Jordanian universities need to embrace new policies and regulations to improve online learning system adoption and use. Fifth, universities need to encourage the use of online learning systems among students through training courses that aim to explain the usefulness of online learning systems and develop students' IT skills. Sixth, if students have adequate technological skills and a positive perception of interacting with the online learning system, this will lead to successful adoption of the online learning system. Overall, the results of this research propose novel insights and implications for decision-makers to successfully ensure the adoption and use of online learning systems during the COVID-19 pandemic.

As with any research, this research has some limitations. First, self-reporting bias may be a limitation, particularly when students are asked about their academic achievements. Therefore, future researchers could conduct a qualitative study to expand our understanding of the factors that impact online learning systems regardless of selfreporting bias from the participants. Second, some caution should be taken when generalizing this study's results to the context of a developed country. Consequently, future researchers could conduct studies that focus on the contexts of developed countries.

\section{Appendix 1. Instrument constructs and items}

\begin{tabular}{ll}
\hline Construct & Items \\
\hline Perceived Usefulness (PU) & $\begin{array}{r}\text { PU-1 Using the university online learning system supports a critical part } \\
\text { of my student life } \\
\text { PU-2 Using the university online learning system enables me to access a } \\
\text { lot of facilities (e.g., library) within my student life } \\
\text { PU-3 Using the university online learning system will improve services } \\
\text { (fast speeds) and save time } \\
\text { PU-4 Overall, the university online learning system is useful } \\
\text { PEU-1 It is easy for me to use the university online learning system } \\
\text { PEU-2 It is easy to learn how to use the university online learning system } \\
\text { PEU-3 It is easy to remember how to use the university online learning } \\
\text { system } \\
\text { PEU-4 Overall, the university online learning system is easy to use }\end{array}$ \\
\hline
\end{tabular}




\begin{tabular}{ll}
\hline Construct & Items \\
\hline Subjective Norms (SN) & SN-1 People who are important to me would think that I should use the \\
university online learning system \\
SN-2 People who are influential to me would think that I should use the \\
university online learning system \\
SN-3 People whose opinions are valued by me would prefer that I use the \\
university online learning system \\
SN-4 People around me have encouraged me to use the university online \\
learning system \\
SN-5 Most students in my group/department use the university online \\
learning system frequently \\
ST-1 I trust the university online learning system to know things I do not \\
know \\
ST-2 I would base an important decision on advice I received from the \\
university online learning system \\
ST-3 The university online learning system has high integrity \\
AT-1 I always enjoy using the university online learning system \\
AT-2 I am positive about using the university online learning system \\
AT-3 I think that using the university online learning system is a good \\
idea \\
AT-4 I want to be among the first people to try out new functions of the \\
university online learning system \\
AT-5 I always consider the university online learning system as my first \\
choice \\
INT-1 I will definitively keep using the university online learning system \\
INT-2 I will use the university online learning system on a regular basis \\
in the future \\
INT-3 I expect that the university online learning system will make \\
everything easier in the future \\
INT-4 It is worth using the university online learning system \\
AU-1 How often per week do you visit the university online learning \\
system? \\
AU-2 How many hours do you use the university online learning system \\
every week? \\
Attitude (AT) \\
Antention to use (INT)
\end{tabular}

Funding This research was not financially supported by any party.

Data availability Upon request.

\section{Declarations}

Conflicts of interest No conflicts of interest or competing interests exist among the researchers.

\section{References}

Abdekhoda, M., Dehnad, A., Mirsaeed, S. J. G., \& Gavgani, V. Z. (2016). Factors influencing the adoption of E-learning in Tabriz University of Medical Sciences. Medical journal of the Islamic Republic of Iran, 30, 457 
Adams, D. A., Nelson, R. R., \& Todd, P. A. (1992). Perceived usefulness, ease of use, and usage of information technology: A replication. MIS quarterly, 16(2), 227-247

Ahmi, A., \& Kent, S. (2013). The utilisation of generalized audit software (GAS) by external auditors. Managerial Auditing Journal, 28(2), 88-113. https://doi.org/10.1108/02686901311284522

Aisbitt, S., \& Sangster, A. (2005). Using internet-based on-line assessment: A case study. Accounting Education: an international journal, 14(4), 383-394

Ajzen, I. (1991). The theory of planned behavior. Organizational behavior and human decision processes, 50(2), 179-211

Akter, S., D'Ambra, J., \& Ray, P. (2011). An evaluation of PLS based complex models: the roles of power analysis, predictive relevance and GoF index. Paper presented at the Proceedings of the Seventeenth Americas Conference on Information Systems, Detroit, Michigan August 4th-7th 20111

Al-Ammari, J., \& Hamad, S. (2008). Factors influencing the adoption of e-learning at UOB. Paper presented at the 2nd International Conference and Exhibition for Zain E-learning Center.

Al-Qadi, N., \& Lozi, B. (2017). The Impact of Middle East Conflict on the Jordanian Economy. International Journal of Academic Research in Business and Social Sciences, 7(7), 2222-6990

Al-Rahmi, W. M., Yahaya, N., Aldraiweesh, A. A., Alamri, M. M., Aljarboa, N. A., Alturki, U., \& Aljeraiwi, A. A. (2019). Integrating technology acceptance model with innovation diffusion theory: An empirical investigation on students' intention to use E-learning systems. IEEE Access, 7, 26797-26809

Allen, I. E., \& Seaman, J. (2007). On-line nation: Five years of growth in on-line learning: ERIC.

Almaiah, M. A., Al-Khasawneh, A., \& Althunibat, A. (2020). Exploring the critical challenges and factors influencing the E-learning system usage during COVID-19 pandemic. Education and Information Technologies, 25, 5261-5280

Alshurafat, H., Beattie, C., Jones, G., \& Sands, J. (2020). Perceptions of the usefulness of various teaching methods in forensic accounting education. Accounting Education, 29(2), 177-204. https://doi. org/10.1080/09639284.2020.1719425

Anderson, T. (2008). The theory and practice of on-line learning: Athabasca University Press.

Azjen, I., \& Fishbein, M. (1980). Understanding attitudes and predicting social behavior. Englewood Cliffs.

Bacow, L. S., Bowen, W. G., Guthrie, K. M., Lack, K. A., \& Lon, M. P. (2012a). Online Learning Systems in US Higher Education. ITHAKA.

Bacow, L. S., Bowen, W. G., Guthrie, K. M., Long, M. P., \& Lack, K. A. (2012b). Barriers to adoption of on-line learning systems in US higher education: Ithaka New York, NY.

Barnard-Brak, L., Paton, V. O., \& Lan, W. Y. (2010). Profiles in self-regulated learning in the online learning environment. International Review of Research in Open and Distributed Learning, 11(1), 61-80

Bidabadi, N. S., Isfahani, A. N., Rouhollahi, A., \& Khalili, R. (2016). Effective teaching methods in higher education: requirements and barriers. Journal of advances in medical education \& professionalism, 4(4), 170

Bierstaker, J., Janvrin, D., \& Lowe, D. J. (2014). What factors influence auditors' use of computerassisted audit techniques? Advances in Accounting, 30(1), 67-74

Chugh, R. (2010). E-learning tools and their impact on pedagogy. In K. J. Editors: Ubha DS (Ed.), Emerging Paradigms in Commerce and Management Education (pp. 58-81). Khalsa College Press, Patiala, India: GSSDGS.

Cohen, J. (1988). Statistical power analysis for the behavioural sciences (2nd ed.). Mahwah: L. Erlbaum Associates.

Davis, F. D. (1989). Perceived usefulness, perceived ease of use, and user acceptance of information technology. MIS quarterly, 13(3), 319-340. https://doi.org/10.2307/249008

Davis, F. D., Bagozzi, R. P., \& Warshaw, P. R. (1989). User acceptance of computer technology: a comparison of two theoretical models. Management science, 35(8), 982-1003

Dumpit, D. Z., \& Fernandez, C. J. (2017). Analysis of the use of social media in Higher Education Institutions (HEIs) using the Technology Acceptance Model. International Journal of Educational Technology in Higher Education, 14(1), 5

Duncan, K., Kenworthy, A., \& McNamara, R. (2012). The effect of synchronous and asynchronous participation on students' performance in on-line accounting courses. Accounting Education, 21(4), 431-449

Fornell, C., \& Larcker, D. F. (1981). Structural equation models with unobservable variables and measurement error: Algebra and statistics. In: Sage Publications Sage CA: Los Angeles, CA. 
Fortin, A., Viger, C., Deslandes, M., Callimaci, A., \& Desforges, P. (2019). Accounting students' choice of blended learning format and its impact on performance and satisfaction. Accounting Education, 28(4), 353-383

Franke, G., \& Sarstedt, M. (2019). Heuristics versus statistics in discriminant validity testing: a comparison of four procedures. Internet Research, 29(3), 430-447. https://doi.org/10.1108/ IntR-12-2017-0515

Gangwar, H., Date, H., \& Ramaswamy, R. (2015). Understanding determinants of cloud computing adoption using an integrated TAM-TOE model. Journal of enterprise information management, 28(1), 107-130. https://doi.org/10.1108/JEIM-08-2013-0065

Garrison, D. R. (2003). Cognitive presence for effective asynchronous on-line learning: The role of reflective inquiry, self-direction and metacognition. Elements of quality on-line education: Practice and direction, 4(1), 47-58

Gómez-Ramirez, I., Valencia-Arias, A., \& Duque, L. (2019). Approach to m-learning acceptance among university students: an integrated model of TPB and TAM. International Review of Research in Open and Distributed Learning, 20(3).

Gruszczynski, L. (2020). The Covid-19 Pandemic and International Trade: Temporary Turbulences or Paradigm Shift? European Journal of Risk Regulation, June 2020, 337 - 342. https://doi.org/10. 1017/err.2020.29

Hair Jr, J. F., Hult, G. T. M., Ringle, C., \& Sarstedt, M. (2016). A primer on partial least squares structural equation modeling (PLS-SEM): Sage publications.

Helfaya, A. (2019). Assessing the use of computer-based assessment-feedback in teaching digital accountants. Accounting Education, 28(1), 69-99

Henseler, J., Ringle, C. M., \& Sarstedt, M. (2015). A new criterion for assessing discriminant validity in variance-based structural equation modeling. Journal of the academy of marketing science, 43(1), 115-135

Hsbollah, H. M. (2009). E-learning adoption: the role of relative advantages, trialability and academic specialisation. Campus-Wide Information Systems, 26(1), 54-70. https://doi.org/10.1108/10650 740910921564

Hsbollah, H. M., \& Idris, K. M. (2009). E-learning adoption: the role of relative advantages, trialability and academic specialisation. Campus-Wide Information Systems, 26(1). https://doi.org/10.1108/ 10650740910921564

Hubona, G. S., \& Kennick, E. (1996). The influence of external variables on information technology usage behavior. Paper presented at the Proceedings of HICSS-29: 29th Hawaii International Conference on System Sciences.

Humphrey, R. L., \& Beard, D. F. (2014). Faculty perceptions of on-line homework software in accounting education. Journal of Accounting Education, 32(3), 238-258

Kock, N., \& Lynn, G. (2012). Lateral collinearity and misleading results in variance-based SEM: An illustration and recommendations. Journal of the Association for information Systems, 13(7), 1-40

Kotb, A., Abdel-Kader, M., Allam, A., Halabi, H., \& Franklin, E. (2019). Information technology in the British and Irish undergraduate accounting degrees. Accounting Education, 28(5), 445-464

Kwon, T. H., \& Zmud, R. W. (1987). Unifying the fragmented models of information systems implementation. Critical issues in information systems research. (pp. 227-251). John Wiley \& Sons Inc.

Lee, Y. C. (2006). An empirical investigation into factors influencing the adoption of an e-learning system. On-line information review, 30(5), 517-554. https://doi.org/10.1108/14684520610706406

Lin, H.-F. (2011). An empirical investigation of mobile banking adoption: The effect of innovation attributes and knowledge-based trust. International journal of information management, 31(3), 252-260

Litherland, K., Carmichael, P., \& Martínez-García, A. (2013). Ontology-based e-assessment for accounting education. Accounting Education, 22(5), 498-501

Liu, I.-F., Chen, M. C., Sun, Y. S., Wible, D., \& Kuo, C.-H. (2010). Extending the TAM model to explore the factors that affect Intention to Use an Online Learning Community. Computers \& Education, 54(2), 600-610

Love, N., \& Fry, N. (2006). Accounting students' perceptions of a virtual learning environment: Springboard or safety net? Accounting Education: an international journal, 15(2), 151-166

Mahzan, N., \& Lymer, A. (2014). Examining the adoption of computer-assisted audit tools and techniques. Managerial Auditing Journal, 29(4), 327-349. https://doi.org/10.1108/MAJ-05-2013-0877

Martins, C. B., Steil, A. V., \& Todesco, J. L. (2004). Factors influencing the adoption of the Internet as a teaching tool at foreign language schools. Computers \& Education, 42(4), 353-374 
Mathwick, C., Wiertz, C., \& De Ruyter, K. (2008). Social capital production in a virtual P3 community. Journal of consumer research, 34(6), 832-849

Means, B., Toyama, Y., Murphy, R., Bakia, M., \& Jones, K. (2009). Evaluation of evidence-based practices in on-line learning: A meta-analysis and review of on-line learning studies. Retrieved from http://repository.alt.ac.uk/id/eprint/629

Moon, J.-W., \& Kim, Y.-G. (2001). Extending the TAM for a World-Wide-Web context. Information \& Management, 38(4), 217-230

Moore, J. L., Dickson-Deane, C., \& Galyen, K. (2011). e-Learning, on-line learning, and distance learning environments: Are they the same? The Internet and Higher Education, 14(2), 129-135

Munoz-Leiva, F., Climent-Climent, S., \& Liébana-Cabanillas, F. (2017). Determinants of intention to use the mobile banking apps: An extension of the classic TAM model. Spanish Journal of MarketingESIC, 21(1), 25-38

Nunnally, J. C. (1994). Psychometric theory 3E: Tata McGraw-hill education.

Pavlou, P. A. (2003). Consumer acceptance of electronic commerce: Integrating trust and risk with the technology acceptance model. International journal of electronic commerce, 7(3), 101-134

Pedrosa, I., Costa, C. J., \& Aparicio, M. (2020). Determinants adoption of computer-assisted auditing tools (CAATs). Cognition, Technology \& Work, 22(3), 565-583

Peng, J., \& Abdullah, I. (2018). Building a market simulation to teach business process analysis: Effects of realism on engaged learning. Accounting Education, 27(2), 208-222

Perera, L., \& Richardson, P. (2010). Students' use of on-line academic resources within a course web site and its relationship with their course performance: An exploratory study. Accounting Education: an international journal, 19(6), 587-600

Sarstedt, M., \& Cheah, J.-H. (2019). Partial least squares structural equation modeling using SmartPLS: a software review. Journal of Marketing Analytics, 7(3), 196-202

Shbail, M., \& Shbail, A. (2020). Organizational climate, organizational citizenship behaviour and turnover intention: Evidence from Jordan. Management Science Letters, 10(16), 3749-3756

Simadi, F. A., \& Nahar, G. S. (2009). Refugees in Jordan: sociological perspective. Social Responsibility Journal, 5(2), 257-264

Sullivan, G. M., \& Feinn, R. (2012). Using effect size-or why the P value is not enough. Journal of Graduate Medical Education, 4(3), 279-282.

Taylor, S., \& Todd, P. (1995). Assessing IT usage: The role of prior experience. MIS quarterly, 561-570.

Torsello, M., \& Winkler, M. (2020). Coronavirus-infected international business transactions: A preliminary diagnosis. . European Journal of Risk Regulation, June 2020396 - 401. https://doi.org/10. 1017/err.2020.30

Turnbull, D., Chugh, R., Luck, J. (2021). Issues in learning management systems implementation: A comparison of research perspectives between Australia and China Education and Information Technologies 1-22 https://doi.org/10.1007/s10639-021-10431-4

Uwizeyemungu, S., Bertrand, J., \& Poba-Nzaou, P. (2020). Patterns underlying required competencies for CPA professionals: a content and cluster analysis of job ads. Accounting Education, 29(2), 109-136

Venkatesh, V., \& Davis, F. D. (1996). A model of the antecedents of perceived ease of use: Development and test. Decision sciences, 27(3), 451-481

Venkatesh, V., \& Davis, F. D. (2000). A theoretical extension of the technology acceptance model: Four longitudinal field studies. Management science, 46(2), 186-204

Venkatesh, V., Morris, M. G., Davis, G. B., \& Davis, F. D. (2003). User acceptance of information technology: Toward a unified view. MIS quarterly, 27(3), 425-478

Yadegaridehkordi, E., Shuib, L., Nilashi, M., \& Asadi, S. (2019). Decision to adopt on-line collaborative learning tools in higher education: A case of top Malaysian universities. Education and Information Technologies, 24(1), 79-102

Publisher's Note Springer Nature remains neutral with regard to jurisdictional claims in published maps and institutional affiliations. 


\section{Authors and Affiliations}

Hashem Alshurafat ${ }^{1}$ (D) Mohannad Obeid Al Shbail ${ }^{2}$ (D)

Walid Muhammad Masadeh ${ }^{1}$ (D) Firas Dahmash ${ }^{1}$. Jebreel Mohammad Al-Msiedeen ${ }^{3}$

Mohannad Obeid Al Shbail

mohannadobeid87@aabu.edu.jo

Walid Muhammad Masadeh

drwaleed@hu.edu.jo

Firas Dahmash

Firas@hu.edu.jo

Jebreel Mohammad Al-Msiedeen

Dr.Jebreel@ttu.edu.jo

1 Department of Accounting, Faculty of Economics and Administrative Sciences, The Hashemite University, P.O. Box 330127, 13133 Zarqa, Jordan

2 Department of Accounting, Faculty of Economics, and Administrative Sciences, Al Al-Bayt University, P.O. BOX 130040, 25113 Mafraq, Jordan

3 Tafila Technical University, Tafila, Jordan 